\title{
Parboiling paddy rice with watermelon (citrullus lanatus) juice
}

\section{Summary}

Watermelon production has become important in West Africa, but the transformation of this fruit rich in water and micronutrients is a weak link of the sector. The objective of this process is to develop new technologies of using watermelon. The process consists in parboiling paddy rice with watermelon juice. Paddy rice is spread on trays to solar dry and then the drying is finalized in the shade. This system reduced moisture content of paddy rice below 13\% for its conservation and shelling. This new transformation process significantly increases the content of L-citrulline and L-arginine two amino acids that play an important role in human metabolism.

\section{Materials and methods}

\section{Watermelon juice production}

Treatments (Figure 1)

i. Water washing.

ii. Cutting.

NB: Inner parts of the watermelon must be scraped to collect the maximum amount of juice and flesh.

i. Complete grinding of the watermelon contents into juice.

ii. Filtration of the watermelon juice in order to separate the solid and liquid elements.

NB: Filtration can be carried out using a sieve (type ASTM-E 11Pruf-Sieb) with a mesh opening diameter of $3 \mathrm{~mm}$ allowing only the watermelon juice to pass through.

i. Recovery of the watermelon juice in a clean container.

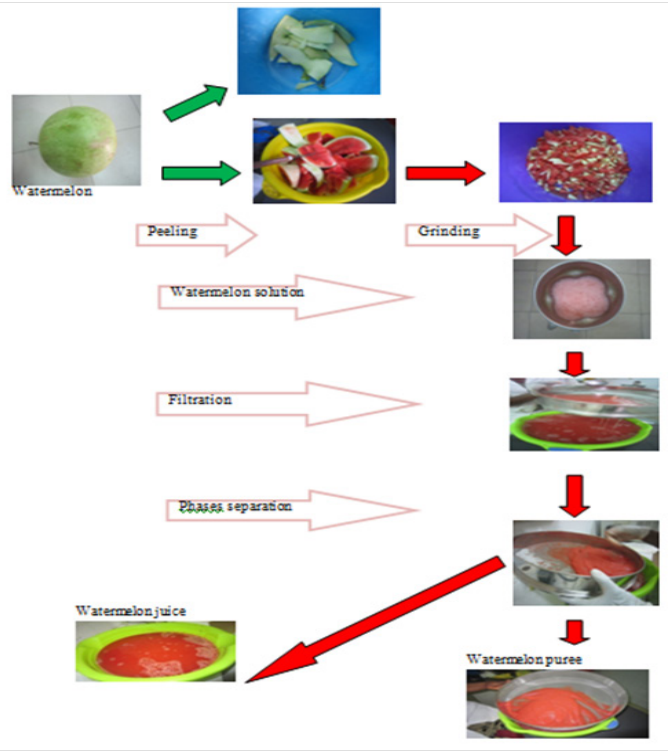

Figure I Production of watermelon juice.
Volume 6 Issue 2 - 2018

\author{
Ndèye Fatou Ndiaye,' Mamadou Sadji,' \\ Cheikna Zongo, ${ }^{2}$ Yves Traore, ${ }^{2}$ Mohamadou \\ Diop Sall, ${ }^{3}$ Alfred Traore ${ }^{2}$ \\ 'Institut de Technologie Alimentaire, Sénégal \\ ${ }^{2}$ Centre de Recherche en Sciences Biologiques Alimentaires \\ et Nutritionnelles, Université Ouaga I Pr Joseph KI-ZERBO, \\ Sénégal \\ ${ }^{3}$ Ecole Supérieure Polytechnique, Université Cheikh Anta Diop, \\ Sénégal
}

Correspondence: Mohamadou Diop Sall, Ecole Supérieure Polytechnique, Université Cheikh Anta Diop, BP 5085, Dakar Fann, Sénégal, Email msmdsall@gmail.com

Received: January 16, 2018| Published: April 16, 2018

\section{Paddy rice treatment}

i. Cleaning and washing.

ii. Paddy rice will be cleaned by winnowing.

iii. Washing paddy rice with water in order to remove stones, sand and immature seeds.

NB: Washing of paddy rice must be performed in a basin containing two paddy volumes for three volumes of water.

i. Draining cleaned paddy rice for a few minutes with a sieve.

ii. Solar drying.

iii. Spreading of cleaned paddy rice on cotton fabric laid on trays.

iv. Exposure of cleaned paddy rice to the sun.

NB: The humidity of cleaned paddy rice should be measured regularly with a moisture meter and the drying should be stopped once the moisture of paddy rice is below $13 \%$.

i. After sun drying, packing and storage of rice.

\section{Parboiling process}

i. Soaking paddy rice in watermelon juice.

ii. Soaking paddy rice in a pot containing watermelon juice that slightly exceed the level of the rice.

iii. Removing the pot from the stove once the watermelon juice temperature has reached the temperature $\left(80^{\circ} \mathrm{C}\right)$.

NB: Paddy rice should be stirred regularly with a wooden ladle and the temperature of the watermelon juice controlled with a thermometer

i. Cooling paddy rice in a covered pot placed at room temperature.

ii. Removing after $18 \mathrm{~h}$ the paddy rice from watermelon juice and rinsing. 
iii. Steaming paddy rice.

iv. Pouring paddy rice into a steamer.

v. Covering with a cotton fabric and steam for 25 to $30 \mathrm{~min}$, until bursting of some paddy grains.

vi. Sun drying of parboiled paddy rice.

vii. Spreading of parboiled paddy rice on trays to solar dry for $4 \mathrm{~h}$.

viii. Drying parboiled paddy in the shade, in a ventilated room.

NB: The moisture content of paddy rice should be below $13 \%$ for its conservation and shelling.

i. Packing of parboiled paddy after drying and storage (in a ventilated room).

\section{Analysis of L-citrulline and L-arginine}

i. Rice was hulled, dried and used to determine L-citrulline and L-arginine contents by HPLC.

ii. The analyses were made using a HPLC (System-Elite LaChrom, Hitachi, Japan) equipped with a DAD detector set at $195 \mathrm{~nm}$, and auto-sampler. L-citrulline and L-arginine contents were quantified following the methods of Jayaprakasha et al. ${ }^{1}$

iii. L-citrulline and L-arginine contents were calculated using standard curves developed with L-citrulline and L-arginine standards (Sigma, USA).

iv. All the measurements were replicated three times and the data are presented as mean $\pm \mathrm{SD}$.

\section{Results and discussion}

L-citrulline content increased to $46.6 \mathrm{mg} / 100 \mathrm{~g}$ (on dry basis) and L-arginine content increased to $17.7 \mathrm{mg} / 100 \mathrm{~g}$ (on dry basis) when rice was soaked with watermelon juice while non-parboiled rice contains traces of L-citrulline $(0.45 \mathrm{mg} / 100 \mathrm{~g})$ and $3.27 \mathrm{mg} / 100 \mathrm{~g}$ of L-arginine. As for rice parboiled with water, the contents are of the order of $0.10 \mathrm{mg}$ / $100 \mathrm{~g}$ and $2.50 \mathrm{mg} / 100 \mathrm{~g}$ respectively for L-citrulline and L-arginine. ${ }^{2}$ Results show that L-citrulline and L-arginine were transferred from watermelon juice to parboiled paddy rice. Watermelon is a natural and rich source of the L-citrulline present in flesh at concentrations ranging from 0.7 to $3.6 \mathrm{~g} / \mathrm{kg}^{3}$
This new process increases significantly in rice, L-citrulline and L-arginine, two amino-acids that play a key role in human metabolism, ${ }^{4,5}$ and then presents a nutritional and health interest. However, further research should be focused on L-citrulline and L-arginine bioavailability. To our knowledge, this is the first study that enhances the levels of L-citrulline and L-arginine in rice using parboiling technique with watermelon juice.

\section{Conclusion}

This study is a new food-based approach for a healthy nutrition related to the valorization of watermelon. On another hand, parboiling rice with watermelon juice process also may be used to minimize post harvest losses.

\section{Acknowledgements}

The undersigned Dr. Prof Mouhamadou Diop SALL certify on the honor that the manuscript sent to you is taken from the work done in my laboratory.

\section{Conflict of interest}

The author declares no conflict of interest.

\section{References}

1. Jayaprakasha GK, Murthy KNC, Patil BS. Rapid HPLC-UV method for quantification of L-citrulline in watermelon and its potential role on smooth muscle relaxation markers. Food Chem. 2011;127(1):240-248.

2. Sadji M, Perkins-Veazie PM, Ndiayen F, et al. Enhanced L-citrulline in parboiled paddy rice with watermelon (Citrullus lanatus) juice for preventing Sarcopenia: A preliminary study. Afr J Food Sci. 2015;9(10):508-513.

3. Collins JK, Wu G, Perkins-Veazie P, et al. Watermelon consumption increases plasma L-arginine concentrations in adults. Nutrition. 2007;23(3):261-266.

4. Suzuki T, Morita M, Hayashi T, et al. The effects on plasma L-arginine levels of combined oral L-citrulline and L-arginine supplementation in healthy males. Biosci Biotechnol Biochem. 2017;81(2):372-375.

5. Wijnands KA, Castermans TM, Hommen MP, et al. Arginine and citrulline and the immune response in sepsis. Nutrients. 2015;7(3):1426-1463. 